\title{
Polímero derivado de mamona acrescido de cálcio, associado ou não à medula óssea autógena na reparação de falhas ósseas ${ }^{1}$
}

\author{
Castor oil plant polymer and calcium associated or not to autogenous bone marrow in bone gaps repair
}

\author{
Ricardo Junqueira Del Carlo ${ }^{2}$ Denise Kawata ${ }^{3}$ Marlene Isabel Vargas Viloria $^{4}$ \\ Damaris Rizzo Oliveira ${ }^{3}$ Alessandra Sayegh Silva ${ }^{3}$ Denise Rodrigues Marchesi $^{5}$ \\ Simone Rezende Galvão ${ }^{3}$ Paulo Azevedo ${ }^{6}$ Betânia Souza Monteiro $^{5}$
}

RESUMO

Foram avaliados o processo de reparação tecidual e o comportamento do implante de polimero vegetal extraído do óleo de mamona acrescido de $40 \%$ de carbonato de sódio, associado ou não à impregnação com medula óssea autógena, em falhas ósseas experimentais em rádios de 30 coelhos e em sitio heterotópico em seis animais. Em quinze coelhos, a falha óssea no rádio direito foi preenchida por cilindros de polímero de mamona (grupo P) com dimensão semelhante à da falha; a falha no rádio direito dos outros coelhos recebeu aspirado de medula óssea autógena junto com o implante (grupo M). A falha óssea no membro esquerdo de cada coelho não recebeu nenhum tratamento e serviu como controle. Os seis coelhos restantes receberam seis implantes no músculo reto abdominal (sitio heterotópico), sendo que, em três animais, os implantes estavam embebidos em aspirado de medula óssea autógena. No local do implante, em ambos os grupos, foi observado aumento da radiopacidade, sem desvio de eixo ósseo ou reabsorção das extremidades ósseas receptoras. $O$ grupo $P$ apresentou áreas irregulares de calcificação na região periférica e sobre o polímero e o $M$ apresentou um padrão de radiopacidade mais intenso, regular e precoce em relação ao $P$. Na avaliação histológica, em ambos os grupos, foi observada formação de tecido ósseo imaturo com tendência à organização, brotos isolados de formação de osso novo sobre o polímero em seus poros superficiais e nos poros internos que se comunicavam. Quando foi associado à medula, o implante permitiu a ocorrência de osteocondução e osteogênese progressiva; houve migração de capilares, tecidos perivasculares e células osteoprogenitoras entre os poros, com tecido fibrovascular invadindo a superficie do implante; a incorporação dos implantes deu-se de maneira lenta e estava incompleta até as nove semanas do estudo; o implante foi biocompativel no periodo avaliado. Em sitio heterotópico, o implante foi incapaz de osteoindução e histologicamente, em ambos os sitios de implantação foram identificadas células gigantes $e$ tecido fibroso envolvente.

Palavras-chave: ricinus communis, implante, enxerto ósseo.

\section{ABSTRACT}

In order to evaluate tissue repair after the use of castor oil polymer implant additioned with $40 \%$ sodium carbonate, isolated or associated to autogenous bone marrow in heterotopic site and in experimental bone gaps in radii of rabbits, 30 White New Zealand rabbits were submitted to bilateral radial ostectomy. In 15 rabbits the bone gap of the right side was filled with polymer cylinders (group P) of similar size of the gaps; the remaining rabbits received autogenous bone marrow with the implant (group $M$ ). The bone defects of the left limb did not receive any treatment and served as control. Six rabbits received 6 implants in the Rectus abdominus muscle (heterotopic site) and in three of these rabbits the implants was associated with bone marrow. In the radiographic study both groups presented increased radiopacity at the implant site without bone axis deviation or resorption of the receptor bone ends. Group $P$ presented

\footnotetext{
${ }^{1}$ Apoio financeiro $\mathrm{CNPq}$.

Viçosa, MG. E-mail: ricarlo@ufv.br. Autor para correspondência.

${ }^{3}$ Médico Veterinário. Departamento de Veterinária, UFV.

${ }^{4}$ Médico Veterinário, Doutor, Professor Adjunto, Departamento de Veterinária, UFV.

${ }^{5}$ Graduando, Departamento de Veterinária, UFV.

${ }^{6}$ Cirurgião Dentista, autônomo.
}

${ }^{2}$ Médico Veterinário, Doutor, Professor Titular, Departamento de Veterinária, Universidade Federal de Viçosa (UFV), 36570-000, 
irregular calcification areas at the peripheral region and over the polymer. Group $M$ presented a more intense, regular and precocious radiopacity pattern in relation to group $P$. In microscopical evaluation there was evidence of immature bone tissue formation tending to organize itself, isolated sprouts of neoformed bone over the polymer and its superficial pores. It was concluded that implant allows osteogenenesis and osteoconduction in bone gaps, and bone formation was progressive, especially when additioned bone marrow aspirate; there was capillary, perivascular tissue and osteoprogenitor cells migrating into the pores; with fibrovascular tissue permeating implant surface; implants incorporation was slowly and was found incomplete until 9 weeks; the implant was able to induce foreign body reaction without toxic or secondary reactions to its presence. In heterotopic and orthotopic sites, the implant was not able to induce bone formation, inciting mild foreign-body reaction with giant cells and surrounding fibrous layer.

Key words: ricinus communis, implant, bone graft.

\section{INTRODUÇÃO}

OHARA et al. (1995) concluíram que o polímero não foi tóxico, não produziu reação inflamatória tardia e, quando implantado no osso, foi revestido por uma fina cápsula fibrosa, sem infiltrado inflamatório e, em alguns pontos, houve crescimento ósseo em íntimo contato com o polímero de mamona. Não houve reabsorção dos implantes, nem crescimento ósseo no interior de seus poros, à semelhança do observado por FRASCINO (1998) e RAMALHO (1998), que também referiram ausência de osteoindução. A adição de carbonato de cálcio ao implante aumentou a resistência e a porosidade, favorecendo sua indicação como material de implantação óssea (IGNÁCIO, 1995; CLARONETO, 1997).

IGNÁCIO (1995); OHARA et al. (1995); VILARINHO et al. (1996) e CARVALHO et al. (1997) concluíram que a biocompatibilidade do polímero, com e sem cálcio, pode ser explicada pela pureza de sua estrutura, não contendo solventes, detritos, estabilizadores e produtos de degradação, responsáveis por respostas orgânicas adversas (MARCHANT et al., 1986).

De acordo com WEISS (1986), a formação de uma cápsula fibrosa na interface implante/ hospedeiro deveria ocorrer, preferencialmente, somente nas fases iniciais de sua aplicação. A reação fibrosa, ao invés de proliferação celular osteoblástica, pode ser resultado de instabilidade mecânica ou rejeição biológica (HOLMES et al., 1986).

Em falhas ósseas experimentais, IGNÁCIO (1995) observou formação gradual e progressiva de osso novo a partir das interfaces polímero-osso, iniciando-se por um processo inflamatório decorrente da agressão produzida pelo ato cirúrgico, que diminuiu paulatinamente. A formação fibroblástica foi substituída por lamelas ósseas ao longo do tempo, que se uniram na região central do polímero. Não houve crescimento ósseo através dos poros, mas apenas em sua superfície, com os poros sofrendo compactação progressiva. Não foi observada fagocitose do material, presença de células gigantes do tipo corpo estranho ou qualquer grau de toxicidade.

A presença de osso dentro de poros do material implantado é evidência de osteocondução. Se, por outro lado, a formação de osso ocorre quando o implante é colocado em tecido mole, evidenciando a diferenciação celular, então ele é osteoindutor (WHITE \& SHORS ,1986; Van EEDEN \& RIPAMONTI, 1994; SILVA, 2000).

Várias associações têm sido feitas na tentativa de somar as propriedades desejadas e acelerar o processo de reparação óssea por osso alógeno ou materiais aloplásticos (OLIVEIRA et al., 2000; SILVA, 2000). Neste aspecto, as células osteoprogenitoras do estroma da medula óssea devem ser consideradas a fonte mais produtiva de células que influenciam a osteogênese (BARROS, 2000).

OLIVEIRA et al. (2000) avaliaram o uso da matriz óssea homóloga desmineralizada no preenchimento de falhas ósseas segmentares e concluíram que a capacidade de reparação foi acrescida com a associação de células do estroma medular.

O objetivo deste trabalho foi avaliar as características do processo de reparação tecidual e o comportamento do polímero vegetal extraído de óleo de mamona, adicionado de carbonato de cálcio, isoladamente e associado à impregnação com medula óssea autógena, aplicado em sítio heterotópico e na reparação de falhas ósseas experimentais em rádio de coelhos, em diferentes tempos de evolução.

\section{MATERIAL E MÉTODOS}

O experimento foi conduzido no Departamento de Veterinária da Universidade Federal de Viçosa, em 36 coelhos da raça Nova Zelândia branco, com idade entre cinco e seis meses e peso entre 3 e $4 \mathrm{~kg}$.

Após anestesia dissociativa com tiletamina/ zolazepam ${ }^{\mathrm{a}}\left(15 \mathrm{mg} \cdot \mathrm{kg}^{-1}, \mathrm{IV}\right)$, a falha óssea foi criada cirurgicamente, em ambos os rádios, pela remoção de um segmento osteoperiosteal em todo o seu diâmetro, com $1,5 \mathrm{~cm}$ de comprimento, localizado a $2,5 \mathrm{~cm}$ da articulação rádio-cárpica, por intermédio de serra elétrica circular $^{\mathrm{b}}$, segundo técnica preconizada por HEIPLE et al. (1963). A estabilização do rádio não foi necessária devido a sinostose com a ulna. As 
extremidades da falha foram lavadas com solução fisiológica, os tecidos muscular e subcutâneo foram aproximados com fio absorvívele ${ }^{\mathrm{c}}$ e a síntese da pele foi feita com fio inabsorvível ${ }^{\mathrm{d}}$. A falha criada no rádio esquerdo não recebeu qualquer tipo de implante, constituindo-se em grupo controle.

O polímero preparado com $40 \%$ de carbonato de cálcio, permitiu a confecção dos cilindros, com as dimensões semelhantes às das falhas, foi esterilizado em autoclave $\left(120^{\circ} \mathrm{C}\right.$ e $1,5 \mathrm{~atm}$, por 30 minutos) e posteriormente implantado na falha. Um ajuste adequado e a aproximação da musculatura mantiveram o polímero no lugar, tornando desnecessário o uso de fixação interna ou externa.

A medula óssea foi obtida por aspiração percutânea da crista ilíaca dos coelhos, durante o procedimento cirúrgico de implantação do polímero, segundo BARROS (2000). O material coletado, cerca de $1,0 \mathrm{ml}$, foi colocado sobre o implante, impregnandoo já no leito receptor e imediatamente após a coleta.

Para avaliar o comportamento do polímero na reparação das falhas ósseas, foram utilizados 15 coelhos, separados em três grupos experimentais $\left(\mathrm{P}_{1}\right.$, $\mathrm{P}_{2}$ e $\mathrm{P}_{3}$ ). Para o polímero associado à medula óssea autógena, foram utilizados outros 15 coelhos, também separados em três grupos iguais $\left(\mathrm{M}_{1}, \mathrm{M}_{2}\right.$ e $\left.\mathrm{M}_{3}\right)$. Os animais foram sacrificados aos 21, 42 e 63 dias após a implantação, permitindo a coleta de material para exame microscópico.

Nos rádios operados, a avaliação radiográfica foi realizada em radiografias convencionais ${ }^{\mathrm{e}}$, obtidas na incidência mediolateral, tanto nos membros que receberam implante quanto nos controles, realizadas no dia 1 (dia da implantação) e nos dias 7, 15, 42 e 63 após as cirurgias. Foi avaliada a radiopacidade na área do implante e na interface osso/implante e o comportamento do polímero na falha.

Para a avaliação microscópica, foram coletados ambos os rádios de três animais de cada grupo experimental. Após fixação em formol tamponado, os fragmentos ósseos foram colocados em solução descalcificadora [citrato de sódio $(450 \mathrm{~g})$, água destilada (3,4 litros), ácido fórmico (1,125 litros)] incluídos em resina acrílica, submetidos a cortes longitudinais, envolvendo a área de implantação e tecido ósseo remanescente proximal e distal. Em seguida, foram corados por hematoxilina/eosina e azul de toluidina/borato de sódio. Foram avaliados, no membro direito, a integridade do implante, presença de osso novo formado, presença de reação fibrovascular e tipo de tecido na transição implante/ osso.
Em dois coelhos de cada grupo, à época da eutanásia, e sob microscopia de fluorescência foi avaliada marcação do crescimento ósseo com tetraciclina $^{\mathrm{f}}$, que foi aplicada por três dias consecutivos, na dosagem de $30 \mathrm{mg} . \mathrm{kg}^{-1}$, até 48 horas antes da coleta, segundo VOLPON (1985).

Para avaliar as capacidades osteindutora e osteocondutora, sem influência do foco de fratura, seis coelhos receberam implantes no músculo reto abdominal (sítio heterotópico), de seis fragmentos de polímero acrescido de carbonato de cálcio, nas dimensões $0,5 \times 0,5 \times 0,2 \mathrm{~cm}$, sendo que, em três coelhos, os fragmentos foram embebidos em medula óssea autógena. Dois fragmentos e o tecido mole circundante foram coletados às duas, quatro e seis semanas após implantação em cada coelho, para exames de fluorescência da tetraciclina e histológicos. Foram considerados o infiltrado celular, a lesão tissular ao redor do implante e a presença de tecido osteóide ou osso novo.

\section{RESULTADOS E DISCUSSÃO}

Radiograficamente, nos rádios controle a área de ostectomia apresentava-se bem definida, delimitando a falha e, na primeira e segunda semanas após a cirurgia, foram identificados pontos de radiopacidade na extremidade da falha, distribuídos de forma irregular e escassa. Na sexta e nona semanas, estes pontos foram mais visíveis, ocupando uma área maior, mas predominantemente nas porções mais periféricas da falha, caracterizando atividade osteogênica, com esclerose óssea e reabsorção. Em quatro coelhos (27\%) observou-se desvio dos fragmentos proximal e distal do rádio.

A avaliação radiográfica do polímero, no pós-operatório imediato, em todos os grupos, demonstrou aspecto homogêneo e poroso, porém com menor radiopacidade em relação à estrutura óssea receptora. No grupo $\mathrm{P}$, na terceira semana, foram observadas áreas irregulares de radiopacidade na região de implantação e ocupando o defeito em suas porções periféricas. Em $100 \%$ dos animais a interface polímero/osso receptor encontrava-se radiolucente nas radiografias iniciais e foi ganhando radiopacidade nos exames posteriores; as áreas de radiopacidade foram mais intensas a partir do periósteo receptor, sendo freqüente a participação do periósteo da ulna, conferindo radiopacidade local. Não houve reabsorção das extremidades receptoras do implante, nem desvio dos fragmentos ósseos.

Já no grupo M, o padrão de radiopacidade foi mais intenso, regular e precoce, quando comparado 
ao P. Essas condições foram progressivas em relação ao tempo, observando-se focos de radiopacidade na área de implantação (Figura 1) e proliferação periosteal a partir das extremidades ósseas receptoras. O periósteo da ulna apresentou-se mais radiopaco sob o polímero em $80 \%$ dos animais, a partir da segunda semana.

Nesta pesquisa, foi observado que o polímero, quando colocado entre os ossos receptores, transferiu carga por eles, determinando-lhes função e, conseqüentemente, manutenção da forma, atuando também como espaçador que permitiu o crescimento ósseo em sua superfície e poros, o que não aconteceu no grupo controle, pois, na sua ausência, foi observada reabsorção das extremidades ósseas e desvio de alinhamento em $27 \%$ dos rádios.

Nos animais do grupo $M$, foi evidenciado que os poros do polímero e sua higroscopia foram veículos para a medula óssea. Da mesma maneira que a observada por BARROS (2000) e comprovada pelos achados radiográficos e histológicos desta pesquisa, ela participou efetivamente, como doadora de células para o processo osteogênico local, conferindo reparação mais acentuada e precoce ao grupo $\mathrm{M}$, quando comparado ao grupo P.

Ao longo do tempo de avaliação radiográfica da interface polímero/osso receptor, verificou-se a diminuição da radiolucência, mas com delimitação evidente, determinando osteointegração incompleta, correspondendo, como confirmado pela microscopia de luz, à presença de tecido fibroso de reparação associado a pontos de formação de osso novo, a partir do fragmento receptor. Também, nas observações radiográficas sucessivas, em ambos os grupos, não foram observados indicativos de que estaria ocorrendo reabsorção do polímero, mas foram evidentes as áreas de radiopacidade na região do implante.

$\mathrm{Na}$ avaliação histológica dos rádios controle, quando houve atividade osteogênica nas linhas de osteotomia, a reparação aconteceu de forma desorganizada. A observação de tecido conjuntivo fibroso, na região da falha entremeada com brotos de tecido ósseo nos rádios controle, remete aos dados de BOLANDER \& BALIAN (1986)os quais relataram que falhas ósseas deixadas sem preenchimento desenvolvem lamelas ósseas de regeneração de maneira desorganizada, com predominância de tecido conjuntivo fibroso.

No grupo $\mathrm{P}_{1}$, aos 21 dias, o polímero apresentou-se envolto por camada de tecido fibroso, com infiltrado inflamatório moderado. Estava íntegro, com poros de vários tamanhos, sem indícios de reabsorção, com transição implante-osso relativamente bem ajustada. Em alguns espécimes, entre o tecido ósseo e o material implantado, foi observada moderada

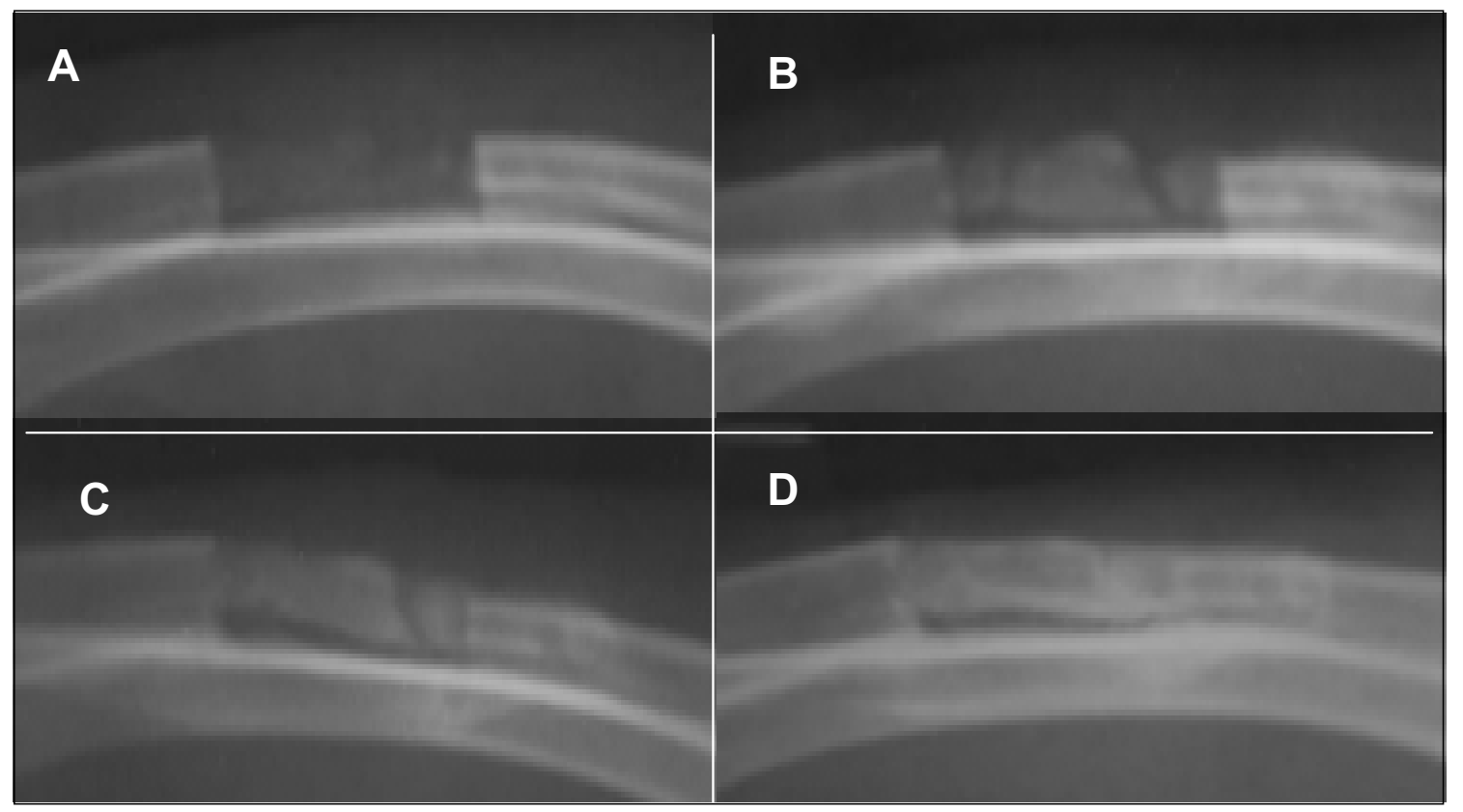

Figura 1 - Radiografia da região operada de um coelho do grupo M. Radiopacidade na região do polímero (A, 7 dias), que se tornou mais intensa em radiografias seriadas $(\mathrm{B}, \mathrm{C}$ e $\mathrm{D}, 21,42$ e 63 dias, respectivamente).

Ciência Rural, v. 33, n. 6, nov-dez, 2003. 
faixa de tecido conjuntivo. Na totalidade das amostras, foi observada reação proliferativa a partir do periósteo receptor.

Aos 42 dias $\left(\mathrm{P}_{2}\right)$ o crescimento ósseo foi discreto e restrito a algumas áreas periféricas e ao periósteo da ulna sob o polímero, existindo crescimento pelos poros superficiais e intercomunicantes do implante. Foi observada a presença de neovascularização e de células gigantes multinucleadas nas avaliações iniciais, da mesma maneira que VILARINHO et al. (1996) encontraram após implantação do polímero na câmara anterior do olho de camundongos.
Apesar da presença de cápsula fibrosa ao redor do implante e de células gigantes (Figura 2), não foram observadas reações locais ou sistêmicas intensas, como extrusão ou formação de fístulas durante o período de experimentação. Esses dados estão de acordo com COSTA \& SCHALL (1992), IGNÁCIO (1995), OHARA et al. (1995), CARVALHO et al. (1997) e RAMALHO (1998), que, ao utilizarem o mesmo material, destacaram sua biocompatibilidade.

O processo inflamatório observado, tanto no abdômen quanto na região da falha óssea, mais intenso nos períodos iniciais, foi conseqüência da

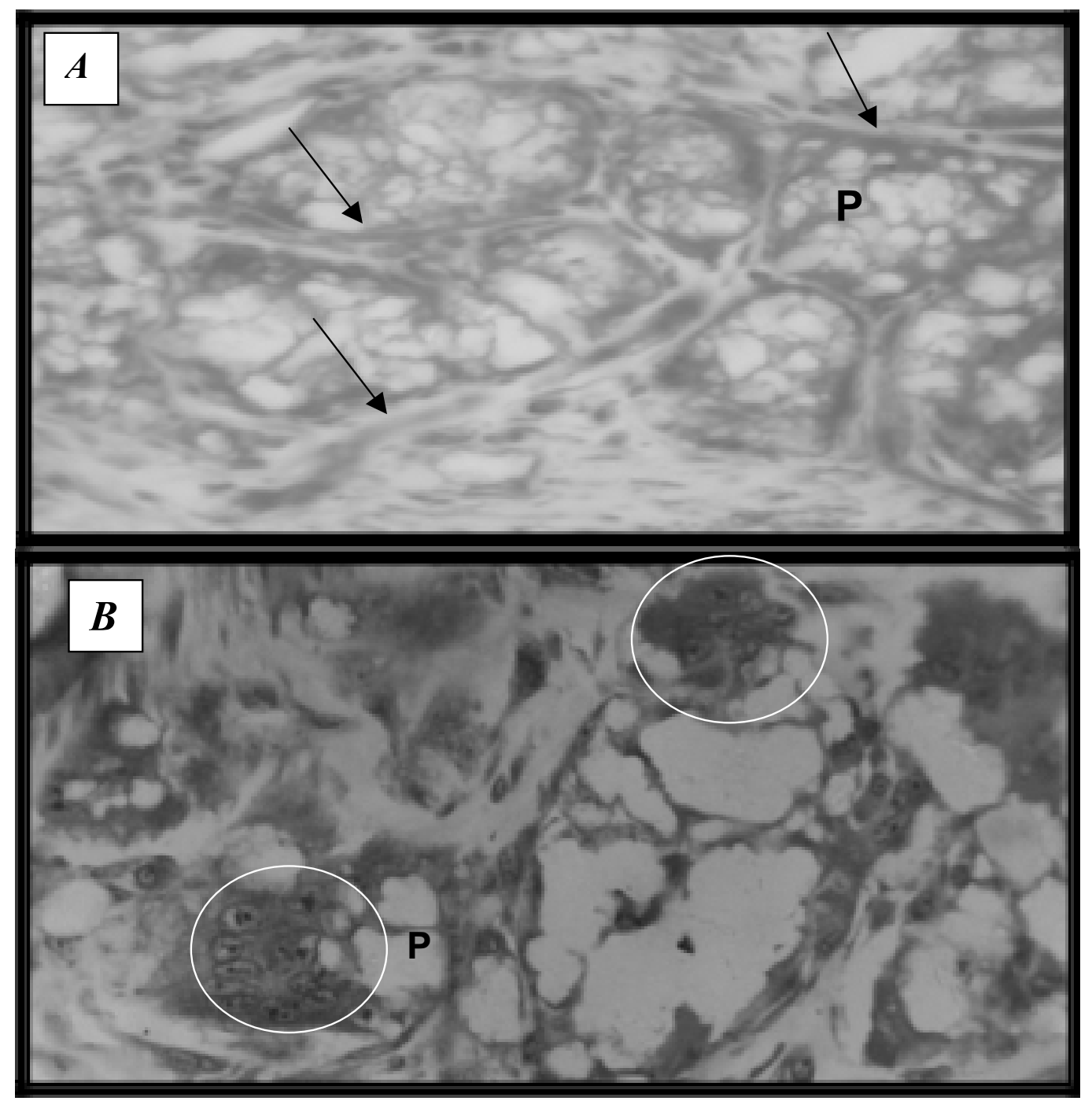

Figura 2 - A. Polímero (P) envolvido por tecido fibroso (setas). Grupo P, 63 dias após a implantação. Azul de toluidina/borato de sódio. 20X. B. Células gigantes multinucleadas (círculos) nas proximidades do polímero (P) implantado no rádio. Grupo P, 42 dias, Azul de toluidina/borato de sódio. 400X. 
agressão cirúrgica, concordando com IGNÁCIO (1995), bem como a presença de tecido fibroso envolvente e de células gigantes foi uma tentativa de o organismo isolar e absorver, respectivamente, o material estranho implantado, comum em fios de sutura, implantes plásticos, dentre outros.

Aos 63 dias $\left(\mathrm{P}_{3}\right)$, observou-se progressão da proliferação óssea, principalmente a partir dos fragmentos receptores e pontos de calcificação na superfície do polímero. Não foi observada reação inflamatória na área ou sinais de reabsorção. Os poros superficiais e os que se comunicavam sofreram preenchimento progressivo por tecido fibroso e ósseo.

Pode-se inferir que, à semelhança dos resultados de IGNÁCIO (1995), o tecido conjuntivo organizado e em contato com a superfície do polímero tende a ser substituído por lamelas ósseas ao longo do tempo, como ele havia observado às 16 semanas. Além disso, a presença de colágeno aumenta a cristalização e permite a ligação de proteínas não colágenas e fatores de crescimento (RIPAMONTI, 1991).

O polímero de mamona adicionado de cálcio apresentou estrutura porosa, mas pode-se afirmar que esta porosidade, conseqüente à sua expansão no processo de polimerização, não representou um verdadeiro sistema canalicular de poros intercomunicantes. No entanto, isso não representou impedimento à osteocondução, com o polímero sustentando o crescimento ósseo em sua superfície e naqueles poros que mantinham contato entre si, como observaram OHARA et al. (1995) e RAMALHO (1998), que referem presença de tecido ósseo neoformado na transição implante-osso e no interior do implante. Segundo WHITE \& SHORS (1986), Van EEDEN \& RIPAMONTI (1994) e SILVA (2000), a presença de osso dentro dos poros do material implantado é evidência de que ele possui propriedades osteocondutoras, que foram confirmadas pelo osso fluorescente marcado pela tetraciclina, nos animais desta pesquisa.

Nas avaliações histológicas seriadas de $\mathrm{M}_{1}, \mathrm{M}_{2}$ e $\mathrm{M}_{3}$, foi observada fibroplasia moderada na transição implante-osso associada a pontos de formação óssea, oriundos dos fragmentos receptores. Em todas as amostras, observou-se formação óssea recobrindo o implante, de maneira concêntrica a partir da periferia da falha. A formação de osso novo, em todas as amostras, ocorreu principalmente a partir do periósteo do rádio receptor e do periósteo da ulna e a partir de brotos de tecido ósseo (Figura 3).
O polímero estava mais compacto, nas observações progressivas, com tecido ósseo preenchendo os poros superficiais, e em alguns espécimes histológicos foi observada permeação do implante por trabéculas ósseas e tecido fibrovascular.

Os resultados demonstraram a ausência de propriedades osteoindutoras no polímero utilizado, pois não foi observada qualquer reação fluorescente nos implantes abdominais, com manutenção de sua forma e sem qualquer evidência de crescimento ósseo à histologia, assim como observaram VILARINHO et al. (1996), FRASCINO (1998) e RAMALHO (1998) em diferentes espécies animais.

Portanto, a ausência de osteoindução nos fragmentos implantados no abdômen evidencia que há dependência de um estímulo para que as células presentes na medula possam realizar osteogênese. Este estímulo estava presente nas falhas ósseas ao contrário do abdômen, quando, neste aspecto, o cilindro foi inócuo. Também foi evidente que a adição da célula tronco medular ao implante, num ambiente adequado, representou um somatório de propriedades desejáveis, pois, nesta situação, as células medulares foram capazes de osteogênese, e o polímero providenciou suporte à penetração de tecido ósseo, conforme descrito por OLIVEIRA et al. (2000) e SILVA (2000) e confirmado radiograficamente pelos melhores resultados do grupo $\mathrm{M}$ em relação ao $\mathrm{P}$.

\section{CONCLUSÕES}

O polímero de mamona acrescido de cálcio permite a ocorrência de osteogênese e osteocondução, com formação progressiva de osso novo, principalmente quando adicionado de células tronco. Permite também a migração de capilares, de tecidos perivasculares e de células osteoprogenitoras num processo inicial de tecido fibrovascular invadindo a estrutura porosa superficial, seguido da deposição direta de osso. Esse arcabouço passivo também se comporta como um espaçador osteocondutor. O implante é biocompatível e não é capaz de osteoindução.

\section{FONTES DE AQUISIÇÃO}

a- Zoletil 50, Virbac.São Paulo, SP.

b- Regular double cutting $(22,22 \mathrm{~mm} \mathrm{X} \mathrm{0,6mm).} \mathrm{Dentorium.}$ New York.

c- Catgut cromado 3-0. Brasmédica. S.A. São Paulo, SP. d- Náilon cirúrgico 3-0. Farma Brasileira. São Paulo, SP. e- Filme 18 X 24 IBF-Medix. São Paulo, SP.

f- Terramicina injetável, Pfizer Ltda. Rio de Janeiro, RJ.

Ciência Rural, v. 33, n. 6, nov-dez, 2003. 


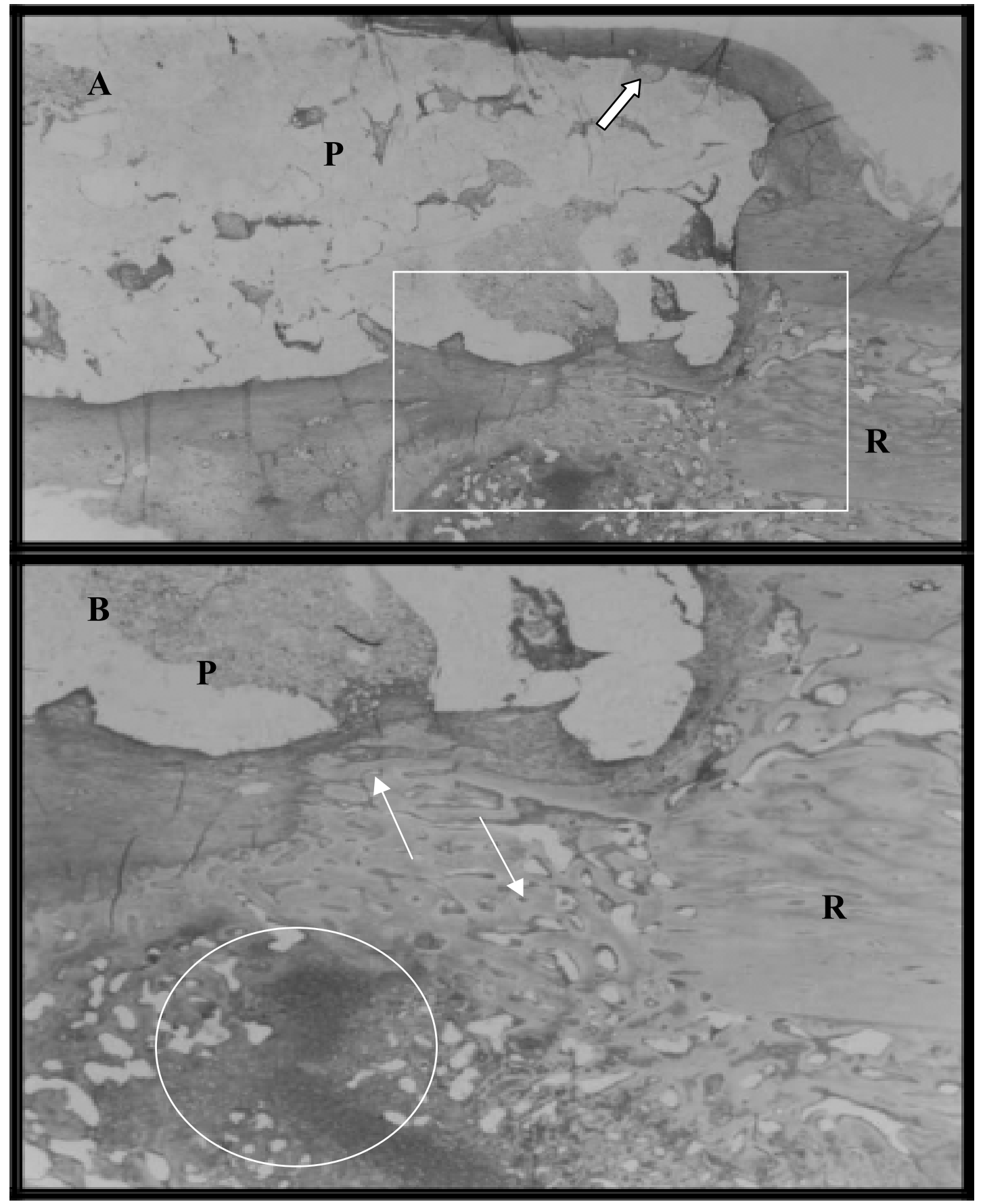

Figura 3 - Grupo M, 21 dias após a implantação. A. Rádio receptor (R), polímero (P), tecido conjuntivo fibroso sobre o polímero (seta). 10X B. Maior aumento da área sob destaque em A (retângulo). Formação óssea imatura (seta) sobre o polímero (P) e a partir de brotos de tecido ósseo/cartilaginoso (círculo) originados do periósteo do rádio (R). 40X. Azul de toluidina/borato de sódio.

\section{REFERÊNCIAS BIBLIOGRÁFICAS}

BARROS, S.V.G. Auto-enxerto percutâneo de medula óssea em falhas segmentares produzidas no rádio de coelhos. 2000. 52f. Dissertação (Mestrado em
Medicina Veterinária) - Universidade Federal de Viçosa.

BOLANDER, M.E.; BALIAN, G. The use of demineralized matrix in the repair of segmental defects. J Bone Joint Surg, v.68A., n.6, p.1264-1274, 1986.

Ciência Rural, v. 33, n. 6, nov-dez, 2003. 
CARVALHO, T.L.L. et al. Histologic and histometric evaluation of rat alveolar wound healing around polyurethane resin implants. Int J Oral Maxillofac Surg, v.26, n.2, p.149-152, 1997.

CLARO NETO, S. Caracterizações físico-químicas de um poliuretano derivado do óleo de mamona utilizado para implantes ósseos. 1997. 127f. Tese (Doutorado em Ciências) - Instituto de Química, Universidade de São Paulo.

COSTA, R.P.; SCHALL, C.H. The use of Ricinus communis (mamona) polymer as a silicone substitute: a new material for prosthesis. In: INTERNATIONAL SYMPOSIUM ON RECENT ADVANCES IN PLASTIC SURGERY, 1992, São Paulo. Proceedings... São Paulo : Brazilian Society of Plastic Surgery, 1992. p.16.

FRASCINO, L.F. Implante de resina poliuretana vegetal em cranioplastia: estudo experimental em coelhos. 1998. 106f. Dissertação (Mestrado em Ciências da Saúde) Faculdade de Medicina de São José do Rio Preto, SP.

HEIPLE, K.G. A comparative study of the healing process following different types of bone transplantation. J Bone Joint Surg, v.45A, n.6, p.1593-1616, 1963 .

HOLMES, R.E.; BUCHOLZ, R.W.; MOONEY, V. Porous hydroxyapatite as a bone graft substitute in metaphyseal defects: a histometric study. J Bone Joint Surg., v.68A, n.4, p.904-911, 1986.

IGNÁCIO, H. Utilização do cimento derivado da mamona no preenchimento de falhas óssea: estudo experimental em coelhos. 1995. 90f. Dissertação (Mestrado em Ortopedia e Traumatologia) - Faculdade de Medicina, Universidade de São Paulo.

MARCHANT, R.E. et al. The biocompatibility of solution cast and acetone-extracted cast biomer. J Biomed Mater Res,v.20, n.6, p.799-815, 1986.

OHARA, G.H. et al. Estudo experimental da biocompatibilidade do polímero poliuretana de mamona implantada intra-óssea e intra-articular em coelhos. Acta Ortop Bras, v.3, n.2, p.6268, 1995.
OLIVEIRA, D.R. et al. Matriz óssea homóloga desmineralizada associada à medula óssea autógena no preenchimento de falhas segmentares em rádio de coelhos. Rev Cien Anim Bras, v.1, Suplemento, p.89, 2000.

RAMALHO, L.T.O. Biocompatibilidade da resina poliuretana vegetal derivada do óleo de mamona: estudos histológicos. In: JORNADA DE CIÊNCIA E TECNOLOGIA DE BIOMATERIAIS, 1998, Vitória. Anais... Vitória : CISBIO Chierice International Society For Biomaterials, 1998. V.1, p.56.

RIPAMONTI, U. Morphogenesis of bone in replicas of porous hydroxyapatite obtained from concersion of carbonate exoskeletons of coral. J Bone Joint Surg, v.73A, n.3, p.692-703, 1991.

SILVA, A.M. Avaliação dos potenciais osteoindutor e osteocondutor da matriz óssea homóloga desmineralizada de coelho. 2000. 62f. Dissertação (Mestrado em Medicina Veterinária) - Universidade Federal de Viçosa.

Van EEDEN, S.P.; RIPAMONTI, U. Bone differentiation in porous hydroxyapatite in baboons is regulated by the geometry of the substratum: implications for reconstructive craniofacial surgery. Plast Reconstr Surg, v.93, n.4, p.959966, 1994.

VILARINHO, R.H.; HeTEM, S.; RAMALHO, L.T.O. Implante de resina de poliuretana vegetal na câmara anterior do olho de camundongo - estudo histológico. In: ODONTOLOGIA DO SÉCULO XXI, 1996, Araraquara, SP. Anais... Araraquara : Faculdade de Odontologia, 1996. V.1, p.25-29.

VOLPON, J.B. A marcação do osso com substâncias fluorescentes. Rev Bras Ortop, v.20, n.5, p.207-210, 1985.

WEISS, C.M. Tissue integration of dental endosseous implants: description and comparative analysis of the fibro-osseous integration and osseous integration systems. J Oral Implant, v. 12, n.2, p.169-214, 1986.

WHITE, E.; SHORS, E.C. Biomaterial aspects of interpore200 porous hydroxyapatite. Dent Clin North Am, v.30, n.1, p.49-67, 1986. 